\begin{abstract}
Ethan Greenberg ${ }^{1}$, Lisa A Hark ${ }^{2 \star}$, Christine Hubert ${ }^{3}$, Brianna Kenney ${ }^{2}$, Courtney B Reamer ${ }^{2}$, Julia A Haller ${ }^{2}$, Robert Bailey ${ }^{4}$ and Irvin Hirsch ${ }^{3}$

${ }^{1}$ Temple University School of Medicine, $3500 \mathrm{~N}$. Broad Street, Philadelphia, PA 19140, USA

${ }^{2}$ Wills Eye Hospital, Department of Research, 840 Walnut Street, Philadelphia, PA 19107, USA

${ }^{3}$ Thomas Jefferson University, Department of Urology, 833 Chestnut Street, Philadelphia, PA 19107, USA

${ }^{4}$ Wills Eye Hospital, Cataract and Primary Eye Care, 840 Walnut Street, Philadelphia, PA 19107, USA

Dates: Received: 28 September, 2015; Accepted: 15 December, 2015; Published: 17 December, 2015

*Corresponding author: Lisa Hark, PhD, RD, Wills Eye Hospital, Department of Research, 840 Walnut St. Philadelphia, PA 19107,USA, Tel: 215-928-3045 Fax: 215-825-9085; E-mail: Ihark@willseye.org

www.peertechz.com
\end{abstract}

Keywords: Dilated fundus examination; Erectile dysfunction; Diabetes mellitus; Diabetic retinopathy; Eye examination

ISSN: 2455-1414

\author{
Research Article
}

\section{Assessing Adherence to Annual Dilated Eye Exam Recommendations in Patients with Diabetes and Erectile Dysfunction}

\section{Abstract}

Aims: This prospective, observational, pilot study assessed adherence rates of annual dilated fundus examinations (DFEs) among patients with diabetes mellitus (DM) and erectile dysfunction (ED) in a university-based practice and identified predictors associated with DFE adherence.

Methods: A total of 56 men who had been diagnosed with ED and type I or type II DM were enrolled in the study and given a 24-question survey assessing their knowledge of DFE recommendations and ocular history. Patients were classified as adherent $(n=39)$ or non-adherent $(n=17)$ to the annual DFE. The differences in demographics, baseline characteristics, and survey responses between the adherent and non-adherent groups were analyzed using Fisher's exact test for the comparison of proportions and Student's t-test for the comparison of means.

Results: The adherent group was more likely than the non-adherent group to be seeing an eye doctor $(p=0.03)$. The most common cited reasons for not seeing an ophthalmologist were "Too busy" $(n=5)$ and "Unable to pay the co-pay" $(n=4)$.

Conclusions: Patients with ED and DM showed a greater adherence to annual DFE recommendations than those in the reported non-ED population. Minimizing the cost barrier and educating about diabetes complications may increase adherence in obtaining a DFE.

\section{Abbreviations}

ED: Erectile Dysfunction; DM: Diabetes Mellitus; DFE: Dilated Fundus Exam; DR: Diabetic Retinopathy; BMI: Body Mass Index; HbA1c: Hemoglobin A1C; TJU: Thomas Jefferson University;

\section{Introduction}

Erectile dysfunction (ED) is a highly prevalent disorder that affects more than 18 million men in the U.S [1]. An estimated $18.4 \%$ of men aged 20 years and older suffer from ED, which is diagnosed as the frequent inability to achieve and maintain an erection firm enough for sexual intercourse [1,2]. During sexual arousal, blood enters the penis through the cavernosal artery; compression of the plexus of subtunical vessels traps blood in the penis, increasing pressure within the lacunar space, making the penis erect [3]. While ED may be linked to hormonal or psychological causes, vascular insufficiency is a common etiology. Men with ED are 2.6 times more likely to have diabetes mellitus (DM), and an estimated $78 \%$ of men with DM have some degree of ED [4-6].

Diabetic retinopathy (DR) also occurs as a result of microvascular pathology [7]. High blood glucose levels cause thickening of capillary basement membranes, pericyte dropout, retinal hemorrhages, microvascular infarcts, ischemia, and retinal edema [8]. An estimated $40 \%$ of patients with DM have DR [9]. There is significant overlap among risk factors for both ED and DR, such as age, smoking, hypertension, hyperlipidemia, obesity, poor glucose control, and an African-American race or Hispanic ethnicity [10].

Despite the risk of retinopathy and guidelines by the American Diabetes Association and the National Eye Institute for annual dilated fundus exams (DFE), $50 \%$ to $65 \%$ of people with diabetes do not adhere to these recommendations [11,12]. Additionally, only $30 \%$ of men with ED seek professional help, resulting in both ED and DR remaining untreated in a large portion of the population [13]. Targeting patients with ED and DM who are seeking treatment in a urology practice may be an effective, focused strategy for improving their access to eye care, increasing adherence to annual DFE recommendations, and improving visual outcomes. This pilot study aimed to 1) assess adherence rates of annual DFE among patients with DM and ED in a university-based practice and 2) identify predictors associated with adherence to annual DFEs in patients with DM and ED.

\section{Materials and Methods}

\section{Subjects}

Thomas Jefferson University (TJU) Institutional Review Board reviewed and approved this study. Patients were identified from TJU Hospital's Department of Urology Sexual Dysfunction Program in Philadelphia, Pennsylvania, USA. Men 18 years of age or older, diagnosed with ED and type I or type II DM were eligible for the study. Other inclusion criteria included fluency in spoken English 
and the ability to engage in informed consent decision making Exclusion criteria included patients diagnosed with hormonal ED or psychological ED and patients who had undergone radical prostatectomy. A total of 56 patients were enrolled in the study. Patients were classified according to their adherence to following annual DFE recommendations, resulting in 39 patients in the "Adherent" group, and 17 patients in the "Non-adherent" group.

\section{Study design}

This was a prospective, observational study. Patients were identified using ICD-9 billing codes for ED and DM in the TJU electronic medical records system. Consent was obtained by Wills Eye Hospital research staff during patients' routine follow-up appointments in the urology clinic. Surveys, consent forms, and self-addressed return envelopes were mailed to patients who met eligibility criteria. These patients were called and notified that a survey was being sent. This 24-question survey assessed patients ocular history as well as their knowledge of DFE recommendations. Additional demographic information and body mass index (BMI), co-morbidities, hemoglobin A1C (HbAlc), metabolic panel, lipid panel, smoking history, and blood pressure results were obtained from patients' electronic records. Patients were compensated with a $\$ 5$ gift card for their participation in the study.

\section{Primary outcome}

The primary outcome of this study was to determine patients self-reported adherence to an annual DFE. Secondary outcomes included patients' awareness of current eye exam recommendations, patients' ability to recall their primary care physician's (PCP) eye exam recommendations, current barriers to obtaining eye exams, and coexisting ocular conditions in patients with ED and DM.

\section{Statistical analysis}

To investigate the difference between the adherent and nonadherent groups, demographics, baseline characteristics, and the survey responses were compared by Fisher's exact test for the comparison of proportions and by Student's t-test for the comparison of means. Statistical analysis was performed by using SAS v9.4 (SAS Institute, Inc, Cary, NC).

\section{Results}

A total of 56 patients were enrolled between November 14, 2012 and January 30, 2014. Demographic information was similar among both groups as shown in Table 1. There were no significant differences in ethnicity, smoking history, drug use, marital status, employment status, insurance status, primary insurance, or highest degree of education received between the groups. However, those who received a graduate degree were more likely to be adherent than those who did not receive a graduate degree. Social alcohol use was reported by $100 \%$ of patients responding in the non-adherent group compared to $48.7 \%$ in the adherent group ( $\mathrm{p}=0.02$ ).

The baseline characteristics are shown in Table 2. Baseline characteristics among the two groups were comparable, with no statistically significant difference in age, BMI, HbAlc, systolic pressure, diastolic pressure, BUN, creatinine, total cholesterol, HDL cholesterol, LDL cholesterol or triglyceride level. The mean BMI for both groups were classified as "obese" (defined as BMI>30) and was 30.2 for the adherent group and 34.4 for the non-adherent group $(\mathrm{p}=0.07)$. The mean HbAlc level was 8.3 , and only $26 \%$ of patients had an $\mathrm{HbAlc}<7.0 \%$. HbAlc was lower (albeit not statistically significant) on average in the adherent group by $1.6 \%$, a $17 \%$ reduction $(7.8 \%$ vs $9.4 \%)$.

A significant percentage of patients in the adherent group, $74.4 \%$, reported that they were seeing an eye doctor at the time, compared to $41.2 \%$ of patients in the non-adherent group ( $\mathrm{p}=0.03$ ). Although ophthalmologists were the primary eye care providers for $84.9 \%$ of patients in the adherent group compared to $62.5 \%$ of those in the non-adherent group, this was not a significant difference. Similarly, $66.7 \%$ of adherent patients could recall being told by their PCP to get an eye exam, compared to $58.8 \%$ of the non-adherent patients (Table 3). Finally, in the adherent group, $92.1 \%$ of subjects, and in the nonadherent group, $88.2 \%$ of subjects accurately knew how often they were supposed to receive eye exams.

A history of any eye disease or eye surgery was more common in the adherent group compared to the non-adherent group (59.0\% vs. $23.5 \%, \mathrm{p}=0.02$ ). A diagnosed pathology was more common in the adherent group compared to the non-adherent group. A significantly higher portion of patients from the adherent group reported a history of DR, compared to the non-adherent group (38.9\% vs. 6.3\%, $\mathrm{p}=0.02$ ). There were no statistically significant differences between the adherent and non-adherent group for a history of eye surgery in the previous year $(\mathrm{p}=0.25)$, any previous history of eye surgery $(\mathrm{p}=0.11)$, cataract surgery $(\mathrm{p}=0.41)$, and a history of glaucoma $(\mathrm{p}=0.40)$. A diagnosis of macular degeneration was noted by 3 patients in the adherent group and none in the non-adherent group. Both groups of patients reported 10 or more years of DM in $\geq 50 \%$ (50\% adherent vs. $52.9 \%$ non-adherent; $\mathrm{p}=0.95$ ).

Among non-adherent patients, the most common cited reasons for not seeing an ophthalmologist were "Too busy" $(\mathrm{n}=5)$, "Unable to pay the co-pay" $(\mathrm{n}=4)$, "No changes to vision" $(\mathrm{n}=3)$, and "Don't have insurance" ( $\mathrm{n}=3$ ) (Table 3).

\section{Discussion}

In this pilot study, patients with ED and DM showed a greater adherence to annual DFE recommendations than those in the reported non-ED population-70\% vs. an estimated range of $35 \%$ to $50 \%[11,12]$. The high adherence rate may reflect patients' awareness of DM complications, specifically DR and ED. An estimated $40 \%$ of all patients with DM have a diagnosis of DR, a similar finding to the adherent group with ED in this study [14]. The more symptomatic patients are, the more likely they are to follow-up with monitoring their disease [11]. Despite increased adherence to exams, only $30 \%$ of patients were in good glycemic control indicated by an $\mathrm{HbAlc}<7.0 \%$. This is important because blood-sugar control is essential to slowing the progression of retinopathy $[15,16]$. Patients with a graduate level education were also more likely to be adherent. It is possible that those with a graduate level of education have increased awareness of the importance of ocular exams, which led to their greater adherence. 
Table 1: Demographic Information.

\begin{tabular}{|c|c|c|c|c|}
\hline & & \multicolumn{2}{|c|}{ Group } & \multirow[b]{2}{*}{$P$ value } \\
\hline & & Adherent $\mathrm{n}(\%)$ & Non-adherent $\mathrm{n}(\%)$ & \\
\hline \multirow{3}{*}{ Ethnicity } & African American & $17(43.6)$ & $11(64.7)$ & \multirow{3}{*}{0.36} \\
\hline & Caucasian & $19(48.7)$ & $5(29.4)$ & \\
\hline & Latino/Hispanic & $3(7.7)$ & $1(5.9)$ & \\
\hline \multirow{4}{*}{ Alcohol History } & Abuse & $1(4.76)$ & $0(0)$ & \multirow{4}{*}{0.024} \\
\hline & Hx Abuse & $1(4.76)$ & $0(0.0)$ & \\
\hline & No use & $9(42.9)$ & $0(0.0)$ & \\
\hline & Social Use & $10(47.6)$ & $10(100.0)$ & \\
\hline \multirow{3}{*}{ Current Smoker } & Currently Smokes & $9(23.1)$ & $2(11.8)$ & \multirow{3}{*}{0.68} \\
\hline & Hx of Smoking & $11(28.2)$ & $5(29.4)$ & \\
\hline & No History & $19(48.7)$ & $10(58.8)$ & \\
\hline \multirow{3}{*}{ Drug Use } & Current Use & $1(5.0)$ & $0(0.0)$ & \multirow[t]{3}{*}{1.00} \\
\hline & Hx of Use & $1(5.0)$ & $1(9.1)$ & \\
\hline & Normal & $22(84.6)$ & $8(72.7)$ & \\
\hline \multirow{5}{*}{ Marital Status } & Single & $8(20.5)$ & $5(29.4)$ & \multirow{5}{*}{0.21} \\
\hline & Married & $23(59.0)$ & $9(52.9)$ & \\
\hline & Divorced & $6(15.4)$ & $1(5.9)$ & \\
\hline & Widowed & $2(5.13)$ & $0(0.0)$ & \\
\hline & Other & $0(0.0)$ & $2(11.8)$ & \\
\hline \multirow{5}{*}{ Employment Status } & Unemployed & $3(7.7)$ & $3(17.7)$ & \multirow{5}{*}{0.79} \\
\hline & Part-time & $3(7.7)$ & $1(5.9)$ & \\
\hline & Full-time & $16(41.0)$ & $8(47.1)$ & \\
\hline & Retired & $13(33.3)$ & $4(23.5)$ & \\
\hline & Other & $4(10.3)$ & $1(5.9)$ & \\
\hline \multirow{8}{*}{ Insurance Status } & No Insurance & $0(0.0)$ & $1(5.9)$ & \multirow{8}{*}{0.65} \\
\hline & Medicare Private Insurance & $1(2.6)$ & $0(0.0)$ & \\
\hline & Medicaid & $2(5.1)$ & $0(0.0)$ & \\
\hline & Medicare & $13(33.3)$ & $4(23.5)$ & \\
\hline & Medicare Medicaid & $2(5.1)$ & $1(5.9)$ & \\
\hline & Private Insurance Medicaid & $1(2.6)$ & $0(0.0)$ & \\
\hline & Private Insurance Medicare & $2(5.1)$ & $0(0.0)$ & \\
\hline & Private Insurance & $18(46.2)$ & $11(64.7)$ & \\
\hline \multirow{4}{*}{ Primary Insurance } & No Insurance & $0(0.0)$ & $1(5.9)$ & \multirow{4}{*}{0.44} \\
\hline & Medicaid & $2(5.1)$ & $0(0.0)$ & \\
\hline & Medicare & $15(38.5)$ & $5(29.4)$ & \\
\hline & Private Insurance & $22(56.4)$ & $11(64.7)$ & \\
\hline \multirow{4}{*}{ Highest Degree Received } & Did not graduate high school & $1(2.6)$ & $3(17.7)$ & \multirow{4}{*}{0.12} \\
\hline & High School or GED & $18(47.5)$ & $6(35.3)$ & \\
\hline & $\begin{array}{c}\text { Undergraduate Degree or BA/ } \\
\text { BS }\end{array}$ & $9(23.7)$ & $6(35.3)$ & \\
\hline & $\begin{array}{l}\text { Graduate Degree (Masters, } \\
\text { PhD, MD, JD, etc.) }\end{array}$ & $10(26.3)$ & $2(11.8)$ & \\
\hline
\end{tabular}

In this study, $66.7 \%$ of adherent patients, and $58.9 \%$ of nonadherent patients were able to recall being informed by their PCP to get an eye exam, consistent with previous reports. Interestingly, of the 22 patients who answered "No" or "Don't remember", $100 \%$ believed that they should get an exam at least once every 12 months. Past research has concluded that a recommendation from a PCP was the most significant predictor for receiving an eye exam [17]. This stresses the importance of DM education by primary care physicians. While many patients were aware that they should be getting annual eye exams, many of them did not. In the nonadherent group $88.2 \%$ of the subjects were aware that they should be getting an eye exam "every year", "at least once a year," or "every six months." However, awareness that they should be receiving an annual eye exam did not translate to patients actually receiving an eye exam. The primary barriers reported for not adhering to the annual DFE recommendations were that they were "Too busy" and "Unable to afford the co-pay." Previous studies have reported that cost is a barrier to obtaining a DFE $[18,19]$. Minimizing the cost barrier may provide an avenue to increase adherence in obtaining a DFE.

There are limitations to this study. Patients were targeted men from a university urology practice and were seeking treatment. The patients enrolled in this study represent a highly motivated population seeking treatment in a university hospital setting and may adhere more strongly to physician recommendations. The sample size is small, especially in the non-adherent group and surveying more patients would strengthen the results and conclusion. In addition, an estimated $30 \%$ of ED patients seek treatment in any setting. For 
Table 2: Baseline Characteristics.

\begin{tabular}{|c|c|c|c|c|c|c|c|}
\hline & \multicolumn{7}{|c|}{ Group } \\
\hline & \multicolumn{3}{|c|}{ Adherent Group $n=39$} & \multicolumn{3}{|c|}{ Non-adherent Group n = 17} & \multirow[t]{2}{*}{$P$ value } \\
\hline & $\mathrm{N}$ & Mean (STD) & Median (min, Max) & $\mathrm{n}$ & Mean (STD) & Median (min, Max) & \\
\hline Age & 39 & $57.9(12.3)$ & $59(28-80)$ & 16 & $60.5(9.6)$ & $59.5(43-81)$ & 0.46 \\
\hline BMI & 35 & $31.1(5.6)$ & $30.2(24.7,44.5)$ & 17 & $34.4(7.1)$ & $35(21,45.8)$ & 0.07 \\
\hline Systolic Pressure & 37 & $131.4(15.4)$ & $131(80,161)$ & 17 & $139(21)$ & $132(118,201)$ & 0.14 \\
\hline Diastolic Pressure & 37 & $77.9(9.4)$ & $78(54,102)$ & 17 & $77.3(10)$ & $80(56,96)$ & 0.82 \\
\hline $\mathrm{HbA1c}$ & 23 & $7.8(1.6)$ & $7.8(5.3,10.9)$ & 11 & $9.4(3.2)$ & $9(5.6,16.3)$ & 0.15 \\
\hline BUN & 28 & $17(4.6)$ & $16.5(10,33)$ & 15 & $18.9(14.8)$ & $14(9,68)$ & 0.63 \\
\hline Creatine & 29 & $1.4(1.9)$ & $1.1(0.6,11)$ & 15 & $1.2(0.7)$ & $1(0.7,3.6)$ & 0.61 \\
\hline Total Cholesterol & 26 & $156.2(39.7)$ & $147.5(85,251)$ & 11 & $164.9(42)$ & $155(111,241)$ & 0.55 \\
\hline HDL Cholesterol & 26 & $46.7(16.4)$ & $42.5(21,100)$ & 11 & $45.6(11.6)$ & $46(26,66)$ & 0.85 \\
\hline LDL Cholesterol & 25 & $83(33.5)$ & $81(18,180)$ & 9 & $90.3(30.3)$ & $86(61,165)$ & 0.57 \\
\hline Triglyceride & 26 & $135.9(70.2)$ & $125(49,334)$ & 11 & $139.4(84.8)$ & $119(45,302)$ & 0.90 \\
\hline
\end{tabular}

Table 3: Survey Responses.

\begin{tabular}{|c|c|c|c|c|}
\hline & & \multicolumn{2}{|c|}{ Group } & \multirow[b]{2}{*}{$P$ value } \\
\hline & & Adherent n (\%) & Non-Adherent $\mathrm{n}(\%)$ & \\
\hline \multirow{2}{*}{ Prescription Glasses } & No & $11(28.2)$ & $4(23.5)$ & \multirow{2}{*}{1.00} \\
\hline & Yes & $28(71.8)$ & $13(76.5)$ & \\
\hline \multirow{2}{*}{ Currently Seeing An Eye Doctor } & No & $10(25.6)$ & $10(58.8)$ & \multirow{2}{*}{0.03} \\
\hline & Yes & $29(74.4)$ & $7(41.2)$ & \\
\hline \multirow{4}{*}{ Last Time Pupils Were Dilated } & Past 12 Months & $39(100.0)$ & $0(0.0)$ & \multirow{4}{*}{ N/A } \\
\hline & Between 1 and 2 Years Ago & $0(0.0)$ & $11(68.8)$ & \\
\hline & 2 or More Years Ago & $0(0.0)$ & $4(25.0)$ & \\
\hline & Never & $0(0.0)$ & $1(6.3)$ & \\
\hline \multirow{3}{*}{ Ophthalmologist or Optometrist } & Ophthalmologist Optometrist & $1(3.0)$ & $1(6.3)$ & \multirow{3}{*}{0.18} \\
\hline & Ophthalmologist & $28(84.9)$ & $10(62.5)$ & \\
\hline & Optometrist & $4(12.1)$ & $5(31.3)$ & \\
\hline \multirow{2}{*}{$\begin{array}{l}\text { Told By PCP To Get An Eye } \\
\text { Exam }\end{array}$} & No & $12(33.3)$ & $7(41.2)$ & 0.76 \\
\hline & Yes & $24(66.7)$ & $10(58.8)$ & \\
\hline \multirow{4}{*}{$\begin{array}{l}\text { How Long Have You Had } \\
\text { Diabetes }\end{array}$} & Less Than 1 Year & $1(2.6)$ & $0(0.0)$ & \multirow{4}{*}{0.95} \\
\hline & 1 To 5 Years & $5(13.2)$ & $3(17.7)$ & \\
\hline & 5 Years To 10 Years & $13(34.2)$ & $5(29.4)$ & \\
\hline & More Than 10 Years & $19(50.0)$ & $9(52.9)$ & \\
\hline \multirow{6}{*}{$\begin{array}{l}\text { How Often Should You Get } \\
\text { Examined By An Eye Doctor }\end{array}$} & Every 6 Months & $6(15.8)$ & $4(23.5)$ & \multirow{6}{*}{0.17} \\
\hline & Every Year & $3(7.9)$ & $0(0.0)$ & \\
\hline & At Least Once Per Year & $26(68.4)$ & $11(64.7)$ & \\
\hline & Every Two Years & $0(0.0)$ & $2(11.8)$ & \\
\hline & Every Five Years & $1(2.6)$ & $0(0.0)$ & \\
\hline & Don't Know & $2(5.3)$ & $0(0.0)$ & \\
\hline \multirow{2}{*}{ Eye Surgery Within Last Year } & No & $30(79.0)$ & $16(94.1)$ & \multirow{2}{*}{0.25} \\
\hline & Yes & $8(21.1)$ & $1(5.9)$ & \\
\hline \multirow{2}{*}{ Eye Surgery Ever } & No & $25(65.8)$ & $15(88.2)$ & \multirow{2}{*}{0.11} \\
\hline & Yes & $13(34.2)$ & $2(11.8)$ & \\
\hline \multirow{2}{*}{ Glaucoma } & No & $27(81.8)$ & $15(93.8)$ & \multirow{2}{*}{0.40} \\
\hline & Yes & $6(18.2)$ & $1(6.3)$ & \\
\hline \multirow{2}{*}{ Diabetic Retinopathy } & No & $22(61.1)$ & $15(93.8)$ & \multirow{2}{*}{0.02} \\
\hline & Yes & $14(38.9)$ & $1(6.3)$ & \\
\hline \multirow{2}{*}{ Macular Degeneration } & No & $29(90.6)$ & $16(100.0)$ & \multirow{2}{*}{0.54} \\
\hline & Yes & $3(9.4)$ & $0(0.0)$ & \\
\hline \multirow{2}{*}{ Corneal Ulcer } & No & $33(97.1)$ & $17(100.0)$ & \multirow{2}{*}{1.00} \\
\hline & Yes & $1(2.9)$ & $0(0.0)$ & \\
\hline БY Conoer/M holomo & No & $36(100.0)$ & $15(100.0)$ & \\
\hline Eye Cancer/Melanoma & Yes & $0(0.0)$ & $0(0.0)$ & 1.00 \\
\hline
\end{tabular}




\begin{tabular}{|c|c|c|c|c|}
\hline \multirow{2}{*}{ Cataract Surgery } & No & $32(82.1)$ & $16(94.1)$ & \multirow{2}{*}{0.41} \\
\hline & Yes & $7(18.0)$ & $1(5.9)$ & \\
\hline \multirow{7}{*}{$\begin{array}{l}\text { Reason For Not Having An Eye } \\
\text { Exam In Past Year }{ }^{a}\end{array}$} & Don't Think An Eye Exam Is Needed Every Year & & 2 & \\
\hline & Had An Unpleasant Experience In An Eye Exam & & 1 & \\
\hline & No Changes To Vision & & 3 & \\
\hline & Too Busy & & 5 & \\
\hline & Unable to Pay the Co-pay & & 4 & \\
\hline & Don't Have Insurance & & 3 & \\
\hline & Don't Have Transportation & & 2 & \\
\hline
\end{tabular}

more generalizable studies, patients with ED and DM should be recruited and enrolled from a variety of settings and not just those seeking treatment. In addition, this study uses self-reported data from patients and is subject to recall bias.

Subspecialty clinics treating symptomatic DM patients with diseases such as ED may be particularly effective sites for DR screening. These patients are already seeking eye care at a higher rate, primarily due to their symptoms and higher level of awareness about diabetes complications. The hurdles for overcoming remaining barriers may therefore be relatively easier to achieve. Convenient, low cost telemedicine strategies, such as cell phone and hand-held cameras to take fundus photographs of the retina, are now being implemented nationally and internationally.

\section{References}

1. Kupelian V, Andre AB, Chiu GR, Rosen RC, McKinlay JB (2010) Relative contributions of modifiable risk factors to erectile dysfunction. Results from the Boston Area Community Health (BACH) Survey. Prev Med 50: 19-25.

2. National Institute of Health Public Access (2014).

3. Krane RJ, Goldstein I, Saenz de Tejada I (1989) Impotence. New Eng J Med 321: 1648-1659.

4. Lindau ST, Schumm LP, Laumann EO, Levinson W, O'Muircheartaigh CA et al. (2007) A study of sexuality and health among older adults in the United States. N Eng J Med 357: 762-764.

5. Meena BL, Kochar DK, Agarwal TD, Choudhary R, Kochar A (2009) Association between erectile dysfunction and cardiovascular risk in individuals with type-2 diabetes without overt cardiovascular disease. Int $J$ Diabetes Devel Countries 29: 150-154.

6. Schoenfeld ER, Greene JM, Wu SY, Leske MC (2001) Patterns of adherence to diabetes vision care guidelines. Ophthalmology 108: 563-571.
7. Gore J, Rajfer J (2004) Diabetes and erectile dysfunction. Curr Sex Health Rep 1: 87-91.

8. Qian H, Harris R (2011) Neurovascular interaction and the pathophysiology of diabetic retinopathy. Exp Diabetes Res 2011: ID 693426.

9. Kempen JH, O'Colmain BJ, Leske MC, Haffner SM, Klein R, et al. (2004) The prevalence of diabetic retinopathy among adults in the United States. Arch Ophthalmol 122: 552-563.

10. Racette L, Wilson MR, Zangwill LM, Weinreb RN (2003) PA Sample. Primary open-angle glaucoma in Blacks: a review. Surv Ophthalmol 48: 295-313.

11. Moss SE, Klein R, Klein BEK (1995) Factors associated with having eye examinations in persons with diabetes. Arch Fam Med 4: 529-534.

12. Brechner RJ, Cowie CC, Howie LJ, Herman WH, Will JC, et al. (1993). Ophthalmologic examination among adults with diagnosed diabetes mellitus. JAMA 270: 1714-1718.

13. Kubin M, Wagner G, Fugl-Meyer AR (2003) Epidemiology of erectile dysfunction. Int J Impot Res 15: 63-71.

14. Cheung N, Mitchell P, Wong TY (2010) Diabetic retinopathy. Lancet 376: 124-136.

15. Frank RN (2004) Diabetic retinopathy. N Engl J Med 350: 48-58.

16. ACCORD Study Group; ACCORD Eye Study Group, Chew EY, Ambrosius WT, Davis MD, et al. (2010) Effects of medical therapies on retinopathy progression in type 2 diabetes. N Engl J Med 363: 233-244.

17. Dervan E, Liliis D, Flynn L, Staines A, O'Shea D (2008) Factors that influence the patient uptake of diabetic retinopathy screening. Ir J Med Sci 177: 303308.

18. Griffin-Shirley N, Trusty S, Kelley P, Siew-Jin LK, Macias EP (2004) Barriers to eye care faced by adult hispanics with diabetes. RE view 36: 53-62.

19. Walker EA, Basch CE, Howard CJ, Zybert PA, Kromholz WN, et al. (1997) Incentives and barriers to retinopathy screening among African-Americans with diabetes. J Diabetes Complications 11: 298-306.

Copyright: (c) 2015 Greenberg E, et al. This is an open-access article distributed under the terms of the Creative Commons Attribution License, which permits unrestricted use, distribution, and reproduction in any medium, provided the original author and source are credited. 